\title{
Consequences of barriers and changing seasonality on population dynamics and harvest of migratory ungulates
}

\author{
Bram Van Moorter $^{1}$ (D) . Steinar Engen ${ }^{2}$ - John M. Fryxell ${ }^{3} \cdot$ Manuela Panzacchi $^{1}$ • Erlend B. Nilsen ${ }^{1} \cdot$ Atle Mysterud $^{1,4}$
}

Received: 16 September 2019 / Accepted: 9 June 2020 / Published online: 25 July 2020

(C) The Author(s) 2020

\begin{abstract}
Many animal populations providing ecosystem services, including harvest, live in seasonal environments and migrate between seasonally distinct ranges. Unfortunately, two major sources of human-induced global change threaten these populations: climate change and anthropogenic barriers. Anthropogenic infrastructure developments present a global threat to animal migrations through increased migration mortality or behavioral avoidance. Climate change alters the seasonal and spatial dynamics of resources and therefore the effects of migration on population performance. We formulated a population model with ideal-free migration to investigate changes in population size and harvest yield due to barriers and seasonal dynamics. The model predicted an increasing proportion of migrants when the difference between areas in seasonality or carrying capacity increased. Both migration cost and behavioral avoidance of barriers substantially reduced population size and harvest yields. Not surprisingly, the negative effects of barriers were largest when the population benefited most from migration. Despite the overall decline in harvest yield from a migratory population due to barriers, barriers could result in locally increased yield from the resident population following reduced competition from migrants. Our approach and results enhance the understanding of how global warming and infrastructure development worldwide may change population dynamics and harvest offtake affecting livelihoods and rural economies.
\end{abstract}

Keywords Seasonal migration · Ideal-free distribution · Anthropogenic infrastructure $\cdot$ Mobile agent-based ecosystem services

\section{Introduction}

Many animal populations benefit from seasonal shifts in resource distribution by migrating between seasonally distinct ranges (Fryxell and Sinclair 1988; Avgar et al. 2013). Theoretical studies demonstrate that migration is an evolutionarily stable strategy in environments where

Electronic supplementary material The online version of this article (https://doi.org/10.1007/s12080-020-00471-w) contains supplementary material, which is available to authorized users.

Bram Van Moorter

bram.van.moorter@nina.no

1 Norwegian Institute for Nature Research, Trondheim, Norway

2 Norwegian University of Science and Technology, Trondheim, Norway

3 University of Guelph, Guelph, Canada

4 University of Oslo, Oslo, Norway areas with the highest population net-growth shift markedly between seasons (Holt and Fryxell 2011; Fryxell and Holt 2013), which results in partial or complete migratory populations (Chapman et al. 2011). Migration is thus an adaptive and spatially extensive utilization of resources that enhances individual fitness (Mariani et al. 2016). The large-scale redistribution of individuals following these long-distance migrations results in an ideal-free distribution within each season (Fretwell and Lucas 1969, 1972), but only when migration has negligible cost. Currently, snow deposition and seasonal resource pulses driving migrations are rapidly shifting due to climate change (Middleton et al. 2013; Brown and Mote 2009). In addition, increasing anthropogenic movement barriers are turning terrestrial migration into a globally threatened phenomenon (Berger 2004; Bolger et al. 2008; Harris et al. 2009; Wilcove and Wikelski 2008).

Anthropogenic infrastructure development that has blocked traditional migration corridors causes declines in abundance of the affected migratory populations (Berger 2004; Bolger et al. 2008; Harris et al. 2009; Wilcove 
and Wikelski 2008). Barriers to movement can affect the proportion of migratory individuals in a partial migratory population mainly in two ways (Shepard et al. 2008). First, barriers can increase the cost of migration by increasing mortality risk or energy expenditure associated with crossing the barrier. For instance, collisions with vehicles during road crossings are a common source of mortality for terrestrial animals (Trombulak and Frissell 2000; Shepard et al. 2008). Second, a structure can also act as a barrier by altering animal behavior, i.e., an individual may avoid a barrier resulting in a decreased crossing probability without necessarily a direct effect on its survival (Beyer et al. 2016; Shepard et al. 2008; Jaeger and Fahrig 2004). The latter can be a non-adaptive behavioral response, when mortality risk is low and benefits of migration are high.

At northern latitudes, seasonal contraction of ungulate ranges is driven by snow deposition in fall increasing mortality risk in their highland ranges, while range expansion in the spring is driven by "green waves" of newly emerging, high-quality forage enhancing growth and recruitment of migratory individuals (Bischof et al. 2012; Aikens et al. 2017). Although geographic variation (e.g., altitudinal) in snow depth often drives migratory behavior in northern latitudes, other sources of geographic variation may motivate animals to migrate (Fryxell and Sinclair 1988). Snow deposition is very sensitive to global warming; even moderate emission scenarios alter snow cover markedly, which alter future habitat suitability of migratory ungulates (Rivrud et al. 2019). A reduction in snow cover would expand suitable year-round ranges and lead to a decreasing benefit of migration in northern latitudes. Such changing migratory patterns have far-reaching implications, as migratory animals transport nutrients, energy, and other organisms between disparate locations (Bauer and Hoye 2014).

Many migratory animal populations provide key resources for indigenous people and rural economies often through harvest and have been called "mobile agent-based ecosystem services" (Kremen et al. 2007; Semmens et al. 2011). Optimal harvest strategies of fluctuating populations has received extensive focus both from theoretical (Lande and Engen 1994; Lande et al. 2003) and empirical studies (Forrest and Walters 2009; Sæther et al. 2001); however, these models typically assume a single resident population (Ling and Milner-Gulland 2008). Recent research efforts have extended such approaches to include animal movements into their harvest models, for instance, dispersal movements in a metapopulation (e.g., Brooks and Lebreton 2001; Costello and Polasky 2008; Neubert 2003; Salinas et al. 2005; Sanchirico et al. 2001) or dispersal movements with protected areas (e.g., Křivan and Jana 2015). Nilsen et al. (2009) found that high levels of migration resulted in a coupling of seasonal ranges, which led to an economic loss, when harvest on both ranges is managed independently.
We investigate how population dynamics and sustainable harvest of (partial) migratory populations are affected by barriers to migration and changes in seasonality. A changing seasonality will affect the relative benefits of being migrant versus resident, while barriers reduce the migration probability or inflict a cost of migration that leads to a violation of the ideal-free distribution across seasons. We build upon the migratory population model used by Fryxell and Holt (2013), but replaced the migratory morphs in that model with behaviorally plastic ideal-free migration (Mariani et al. 2016) and allowed for population harvest. This allowed us to investigate the effects of changing seasonality and movement barriers through both fitness cost and non-adaptive barrier avoidance on population dynamics and harvest strategies.

\section{The model}

\section{Partial migratory population dynamics}

We used the population model presented by Fryxell and Holt (2013), where the dynamics of population size follow a Ricker model (Ricker 1954), with scaled densities (i.e., $N=N^{\prime} / K^{\prime}$, where $N^{\prime}$ is the unscaled population size in spring just prior to the reproduction season and $K^{\prime}$ is the population size at which on average each individual replaces itself during summer. Table 1 provides an overview of all symbols). Following Fryxell and Holt (2013), we assumed recruitment $(r)$ during summer to be density dependent and mortality during winter $(\mu)$ to be density independent. Both assumptions are supported by many empirical studies of ungulates (Sæther 1997; Gaillard et al. 2000).

Assuming non-overlapping generations and using the Ricker formula to represent episodes of summer reproduction, the multiplicative growth rate equals $\exp (r[1-$ $\left.\left.N^{\prime} / K^{\prime}\right]\right)=\exp (r[1-N])$, where $e^{r}$ is the maximum per capita recruitment during summer. Assuming densityindependent winter survival probability $e^{-\mu}$, the number of animals after 1 year at the end of winter is calculated as follows:

$N(t+1)=N(t) \exp (r[1-N(t)]-\mu)$

The (scaled) equilibrium population size $\left(N^{*}\right)$ for this model is (i.e., where $r\left[1-N^{*}\right]-\mu=0$, from Eq. 1):

$N^{*}=1-\frac{\mu}{r}=1-\phi$

The equilibrium population size is thus less than the summer carrying capacity; the difference is given by the ratio $(\phi)$ between mortality $(\mu)$ and recruitment $(r)$; when $\phi \geq 1$, a population is not viable year-round.

The seasonal fitness in an area will fluctuate between $\exp (r[1-N])$ in summer and $\exp (-\mu)$ in winter (Fryxell 
Table 1 Symbols

\begin{tabular}{ll}
\hline Symbol & Meaning \\
\hline$N^{\prime}$ & Unscaled population size in spring prior to reproduction \\
$N$ & Scaled population size $\left(=N^{\prime} / K^{\prime}\right)$ \\
$N^{*}$ & Equilibrium population size $(=\mathrm{N}(\mathrm{t})=\mathrm{N}(\mathrm{t}+1))$ \\
$K^{\prime}$ & Unscaled population size at which individuals replace themselves during summer \\
$\mu$ & Mortality \\
$r$ & Recruitment \\
$\phi$ & Difference between the (scaled) summer and the year-round carrying capacity $(=\mu / r)$ \\
$\theta$ & Seasonality $(=\exp (r)-\exp (-\mu))$ \\
$h$ & Harvest rate \\
$H$ & Proportion harvested $(=1-\exp (-h))$ \\
$c$ & Cost of migration \\
$m$ & Migration probability \\
$\hat{m}$ & Ideal-free migration probability \\
$b$ & Non-adaptive barrier avoidance $(=1-m / \hat{m})$ \\
\hline
\end{tabular}

${ }^{1}$ See main text for further details

and Holt 2013). Similar to Mariani et al. (2016), we define the seasonality $(\theta)$ of an area as the difference between these seasonal fitnesses. Due to the density dependence of the summer fitness, this definition of seasonality is also density dependent. At equilibrium, the seasonality will depend solely on the winter fitness, which can be approximated using a first order Taylor expansion with a very simple expression:

$\theta=\exp \left(r\left[1-N^{*}\right]\right)-\exp (-\mu)=e^{\mu}-e^{-\mu} \approx 2 \mu$

Although at high density the amplitude of the variation in seasonal fitness depends only on the winter mortality rate, it is not intuitive to define seasonality in an area exclusively based on the demographic parameters from that area during a single season. We therefore defined seasonality based on the amplitude of the fitness fluctuation at low population density:

$\theta=\exp (r[1-0])-\exp (-\mu)=e^{r}-e^{-\mu}$

Thus, we define seasonality as the difference between the intrinsic summer recruitment and the winter survival.

Following Fryxell and Holt (2013), we linked two population ranges through the movement of migratory animals, which move with migration probability, $m$, and cost, $c$, after the winter season from one range to the other (see Fig. 1 and in Appendix Fig. 7). For convenience, we

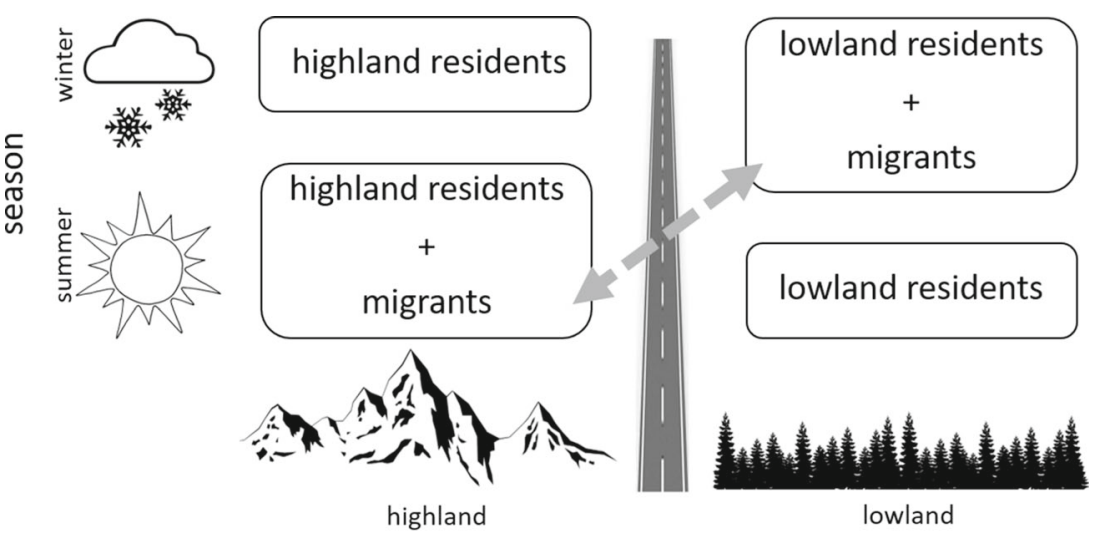

range

Fig. 1 Illustration of migratory events throughout the year between the two ranges: highlands (left) and lowlands (right). The migration barrier is represented by the road in between. During winter (upper row), only highland residents can be found in the highlands, while both residents and potential migrants share the lowland range. During summer (lower row), the highlands are occupied by highland residents together with migrants from the lowland area, while only lowland residents remain in their range. Note that such resident or migrant individuals may not be present for certain parameter combinations, see main text 
will refer to these ranges as either lowland (L) or highland $(\mathrm{H})$, since many ungulate migrations follow strong elevation gradients (Mysterud et al. 2011). However, depending on the ecological context other labels could be more appropriate, e.g., southern and northern range for latitudinal migration; our results and conclusions are not limited to the case of altitudinal migration only. The lowland range is characterized by lower winter mortality (i.e., $\mu_{L} \leq \mu_{H}$ ). Therefore, we assumed during fall only migration from high- to lowland; the so-called "perverse" migrants (sensu Fryxell and Holt 2013) from low- to highland during fall were not considered. All migrants that moved during spring to the highland range move back in the fall together with their offspring to the lowland range for the winter season.

The number of individuals migrating from the lowland range is $m N_{L}^{\prime}$ so that the number of individuals contributing to population regulation in the highland range is $N_{H}^{\prime}+m N_{L}^{\prime}$. Following the population model in Eq. 1, the multiplicative growth rate in the highland range for both residents and migrants equals: $\exp \left(r_{H}\left[1-\left(N_{H}^{\prime}+m N_{L}^{\prime}\right) / K_{H}^{\prime}\right]\right)=$ $\exp \left(r_{H}\left[1-N_{H}-\frac{K_{L}^{\prime}}{K_{H}^{\prime}} m N_{L}\right]\right)$. The number of animals after 1 year at the end of winter on the highland range is calculated as follows:

$N_{H}(t+1)=N_{H}(t) \exp \left(r_{H}\left[1-N_{H}(t)-\frac{K_{L}^{\prime}}{K_{H}^{\prime}} m N_{L}(t)\right]-\mu_{H}-h_{H}^{S}-h_{H}^{W}\right)$

where $e^{-h_{H}^{S}}$ and $e^{-h_{H}^{W}}$ are the probabilities of surviving respectively the summer and winter harvest season in range $H$. We use subscripts to indicate the harvested range and superscripts to indicate the timing of the harvest (see details in the section on "population harvest" below).

The number of animals at the end of winter in the lowland range, $N_{L}$, after 1 year is the sum of residents in $L$ and migrants, which returned to $L$ after the summer on $H$ :

$$
\begin{aligned}
& N_{L}(t+1)=(1-m) N_{L}(t) \exp \left(r_{L}\left[1-(1-m) N_{L}(t)\right]-\mu_{L}-h_{L}^{S}-h_{L}^{W}\right) \\
& +m N_{L}(t) \exp \left(r_{H}\left[1-N_{H}(t)-\frac{K_{L}^{\prime}}{K_{H}^{\prime}} m N_{L}(t)\right]-\mu_{L}-c-h_{H}^{S}-h_{L}^{W}\right)
\end{aligned}
$$

where $e^{-h_{L}^{S}}$ and $e^{-h_{L}^{W}}$ are the probabilities of surviving respectively the summer and winter harvest season in the lowland range. For simplicity, we assumed that migration cost $(c)$ is incurred after summer, so that the fraction of migrants surviving winter is $e^{-\mu_{L}} e^{-c}=e^{-\mu_{L}-c}$. Densitydependent recruitment $(r)$ takes place during summer, which is for migrants in the highland range (i.e., $r_{H}$ ) and in the lowland range for those residents (i.e., $r_{L}$ ), whereas the density-independent winter mortality $(\mu)$ occurs when migrants and residents share their common lowland range.

\section{Population harvest}

We defined harvest on each range as the proportion of the population harvested in Eqs. 5 and 6 during either the summer $\left(H_{H}^{S}\right.$ and $\left.H_{L}^{S}\right)$ or the winter season $\left(H_{H}^{W}\right.$ and $\left.H_{L}^{W}\right)$, we assumed that harvest never occurs during both seasons (i.e., if $H_{H}^{S}>0$ or $H_{L}^{S}>0$, then $H_{H}^{W}=H_{L}^{W}=0$, or if $H_{H}^{W}>0$ or $H_{L}^{W}>0$, then $H_{H}^{S}=H_{L}^{S}=0$ ). The proportion of the population in a range $(H$ or $L)$ surviving the harvest season $(S$ or $W)$ is then $1-H_{\text {range }}^{\text {season }}=$ $\exp \left(-h_{\text {range }}^{\text {season }}\right)$. Whether harvest takes place before or after migration does not affect residents directly (i.e., residents in $H$ experience either $H_{H}^{S}$ or $H_{H}^{W}$, and residents in $L$ either $H_{L}^{S}$ or $H_{L}^{W}$ ); however, for migrants, the timing of harvest will affect whether they experience the same harvest pressure as highland residents during summer $\left(H_{H}^{S}\right)$ or as lowland residents during winter $\left(H_{L}^{W}\right)$.

The long-term equilibrium dynamics of this system, based on Eqs. 5 and 6, is defined in terms of the equilibrium population sizes on the lowland $\left(N_{L}^{*}\right)$ and highland range $\left(N_{H}^{*}\right)$, which are calculated as $N_{L}^{*}=N_{L}(t)=N_{L}(t+1)$ and $N_{H}^{*}=N_{H}(t)=N_{H}(t+1)$, respectively. The overall maximum sustainable yield is then given by the harvest proportions $\left(H_{H}^{S}\right.$ and $H_{L}^{S}$, or $H_{H}^{W}$ and $\left.H_{L}^{W}\right)$ that realize the largest yield (for summer harvest in Eq. 7, and winter harvest in Eq. 8) at equilibrium summed over both ranges. The total long-term yield from summer harvest $Y^{S}$ is the summed yield from residents and migrants on the highland range and residents on the lowland range:

$Y^{S}=H_{H}^{S}\left(N_{H}^{*}+\frac{K_{L}^{\prime}}{K_{H}^{\prime}} m N_{L}^{*}\right)+H_{L}^{S} \frac{K_{L}^{\prime}}{K_{H}^{\prime}}(1-m) N_{L}^{*}$

with the yield scaled by the carrying capacity of range $\mathrm{S}$ $\left(K_{H}^{\prime}\right)$. Similarly, the total yield from winter harvest $Y^{W}$ is the summed yield from the highland range and the lowland range, with the migrants returned to their lowland range for the winter:

$Y^{W}=H_{H}^{W} N_{H}^{*}+H_{L}^{W} \frac{K_{L}^{\prime}}{K_{H}^{\prime}} N_{L}^{*}$

\section{Density-dependent migration with a semi-permeable barrier}

The population dynamics on the lowland and highland range are linked through partial seasonal migration. As more animals migrate (i.e., increasing migration probability, $m$ ) from the lowland range, the density of animals in the lowland range decreases during summer and the summer fitness of residents in that range increases, whereas the density of animals in the highland range increases during summer and the summer fitness of migrants in the highland range decreases (Fig. 2). We assumed an ideal-free 
migration strategy (Mariani et al. 2016), where the idealfree migration probability $(\hat{m})$ equalizes the summer fitness for lowland range residents and migrants, calculated from Eq. 6:

$\exp \left(r_{L}\left(1-(1-m) N_{L}\right)-h_{L}^{S}\right)=\exp \left(r_{H}\left(1-N_{H}-\frac{K_{L}^{\prime}}{K_{H}^{\prime}} m N_{L}\right)-c-h_{H}^{S}\right)$

Since this equation is linear in $m$, the ideal-free migration probability $(\hat{m})$ is calculated as follows:

$\hat{m}=\frac{r_{H}\left[1-N_{H}\right]-r_{L}\left[1-N_{L}\right]-\left(h_{H}^{S}-h_{L}^{S}\right)-c}{\left[r_{L}+r_{H} \frac{K_{L}^{\prime}}{K_{H}^{\prime}}\right] N_{L}}$

Thus, the ideal-free migration probability increases as the difference in saturation between the high- and lowland ranges increases, weighted by their respective levels of summer recruitment. Moreover, it decreases when the cost of migration increases, and when harvest pressure during summer is higher on the highland range than on the lowland range. We assumed omniscient or "ideal" individuals; in reality, however, an individual's knowledge of these parameters will be incomplete. The effects of incomplete knowledge on migration behavior and population dynamics are an interesting avenue for future research.

Interestingly, the ideal-free migration probability is not the migration probability that maximizes the average fitness for the lowland range population (Fig. 2). The migration probability that maximizes the average fitness will be lower than the ideal-free migration probability when $r_{H}>r_{L}$.

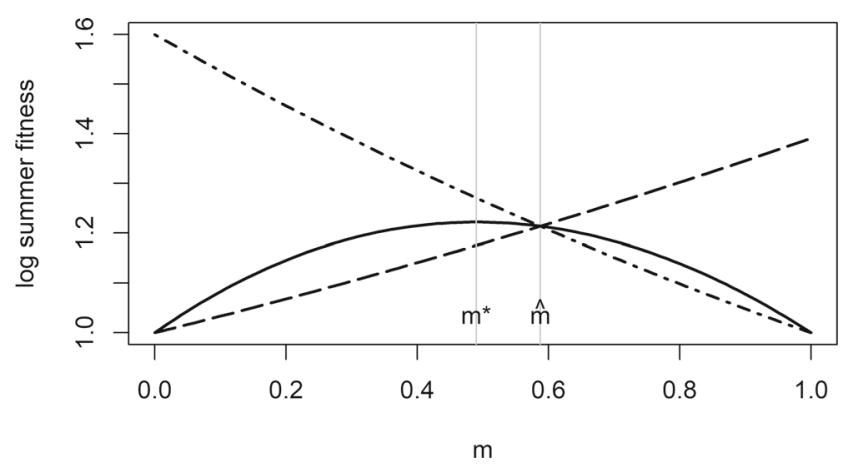

Fig. 2 The summer fitness of the lowland residents (dashed line) and the migrants (dot-dashed line) as a function of the migration probability. The solid line shows the average summer fitness for both movement tactics. The vertical gray lines indicate the idealfree migration probability $(\hat{m})$ - where the fitness of both tactics is equal - at 0.59 , and the migration probability maximizing the average population summer fitness or growth $\left(m^{*}\right)$ at 0.49 . The parameters for Eq. 9 were $r_{H}=0.47, r_{L}=0.33, K_{L} / K_{H}=1, c=0, h_{H}^{S}=h_{L}^{S}$, $N_{H}=0$, and $N_{L}=1$. It is interesting to note that $m^{*}<\hat{m}$; thus, maximum growth of the population at the lowland range is realized at a migration probability below the ideal-free migration probability
Instead, the ideal-free migration probability $(\hat{m})$ is the one that equalizes the summer fitness on the high- and lowland range (Fig. 2). This solution is therefore a Nash-equilibrium (Osborne 2009), since an individual changing its movement tactic would increase the density in the range it selects and experiences a lower fitness than if it would have stayed (Křivan et al. 2008).

The ideal-free migration probability accounts for the fact that migration can be costly $(c>0)$; however, it does assume that animals are "free" to move. In addition to increasing the cost of migration $(c)$, barriers can also affect migration behavior through behavioral avoidance of the barrier (i.e., beyond an adaptive response to an increasing migration cost), which further reduces the probability of migration. This non-adaptive behavioral avoidance effect of a barrier $(b)$ will lead to a lower realized migration probability ( $m$ in Eqs. 5 and 6 ) compared to the ideal-free migration probability in the absence of such a barrier $(\hat{m}$, in Eq. 10):

$m=(1-b) \times \hat{m}$

Thus, a barrier can affect migration probability either through behavioral avoidance, $b$, in Eq. 11, or through the migration cost, $c$, in Eq. 10.

\section{Simulations}

We used $\theta_{L}=0.5$ and $\theta_{H}=0.7$ (see Eq. 4) as reference values for seasonality and $\phi_{L}=\phi_{H}=0.5$ (see Eq. 2) for year-round range performance. The vital rates corresponding to these reference values are $r_{L}=0.31$, $r_{H}=0.41, \mu_{L}=0.15$, and $\mu_{H}=0.21$, similar to those used by Fryxell and Holt (2013). Table 2 shows a summary of the different parameter values used. In addition to this reference with a relatively high year-round range performance, we also provide in Supplementary Figures the results from a scenario with the same seasonality, but with low year-round range performance: $\phi_{L}=\phi_{H}=0.95$ (vital rates: $r_{L}=0.25, r_{H}=0.35, \mu_{L}=0.24$, and $\mu_{H}=0.33$ ). We initialized population sizes in both ranges at 0.01 for all simulations (i.e., $N_{L}(t=0)=N_{H}(t=0)=0.01$ ); we tested the sensitivity to the initial values by comparing with both $N_{H}(t=0)=0.9$ and $N_{L}(t=0)=0.9$. Our results were not affected by these starting values, unless stated otherwise.

First, we investigated the role of seasonality on ideal-free migration by varying the seasonality difference between the high- and lowland range $\left(\theta_{L}=0.5\right.$ and $\left.0.5 \leq \theta_{H} \leq 0.7\right)$ for different year-round population performance $\left(\phi_{L}=\phi_{H}=\right.$ $0.5, \phi_{L}=0.5$ with $\phi_{H}=0.7$, and $\left.\phi_{L}=\phi_{H}=0.95\right)$ in the absence of a barrier $(c=b=0)$. Secondly, we looked into the yield obtained from the total population using the reference values for different harvest probabilities, with 
Table 2 Simulation parameter values

\begin{tabular}{llllllll}
\hline Simulation & $\theta_{L}$ & $\theta_{H}$ & $\phi_{L}$ & $\phi_{H}$ & $\mathrm{~h}$ & $\mathrm{c}$ & $\mathrm{b}$ \\
\hline Reference $^{1}$ & 0.5 & 0.7 & $0.5(0.95)^{2}$ & $0.5(0.95)^{2}$ & 0 & 0 & 0 \\
Seasonality $_{\text {Harvest }}$ & 0.5 & {$[0.5,0.7]^{3}$} & $0.5 / 0.95$ & $0.5 / 0.7 / 0.95$ & 0 & 0 & 0 \\
Migration cost & 0.5 & 0.7 & 0.5 & 0.5 & {$[0,1]^{3}$} & 0 & 0 \\
Barrier avoidance & 0.5 & 0.7 & 0.5 & 0.5 & {$[0,1]^{3}$} & {$[0,1]^{3}$} & $0(0.5)^{2}$ \\
\hline
\end{tabular}

${ }^{11}$ See also Fryxell and Holt (2013);

12 The results from the values within round brackets are shown in appendix

${ }^{13}$ Square brackets denote the range of values explored in the simulation

harvest taking place either during summer or winter, in the absence of a barrier $(c=b=0)$. Finally, we investigated how both migration cost $(0 \leq c \leq 0.15)$ and behavioral avoidance $(0 \leq b \leq 1)$ of barriers influence the population size and the maximum sustainable yield using the reference values.

We used the optim-function with the constrained quasiNewton algorithm (i.e., "L-BFGS-B," Byrd et al. 1995) in $\mathrm{R}$ ( $\mathrm{R}$ Core Team 2016) to find the maximum yield at equilibrium (i.e., the maximum sustainable yield).

\section{Results}

\section{Ideal-free migration in a seasonal environment}

The reference parameter values result in $56 \%$ of the population migrating and $44 \%$ remaining resident yearround in the common lowland range (Fig. 3). However, when the year-round carrying capacity is low $(1-\phi=0.05)$, then $87 \%$ of the population migrates and only $13 \%$ remains resident. Under both scenarios, residents in the highland range cannot persist because they are out-competed by

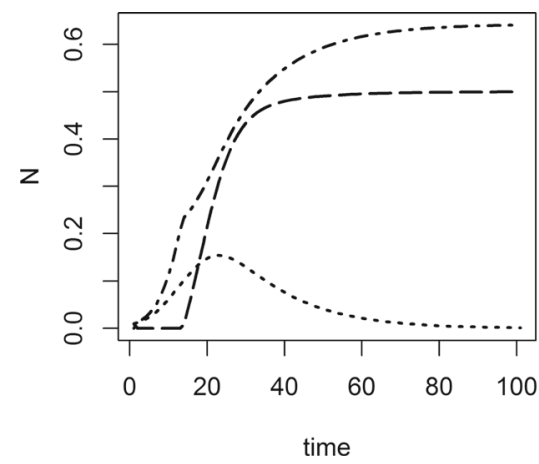

Fig. 3 The population dynamics of the highland residents (dotted line), lowland residents (dashed line), and migrants (dot-dashed line) over 100 years. Both population ranges were initiated at 0.01 . The panel on the left shows results with the reference values (Table 2, and on the right reference values with low year-round carrying capacity, the migrants, who benefit from the lower mortality on the lowland range $\left(\mu_{L}<\mu_{H}\right)$.

More generally, the proportion of migrants increases with increasing differences in seasonality or decreasing year-round carrying capacity of high- and lowland ranges (Fig. 4). The model is capable of producing three main states. First, in the absence of a difference in seasonality $\left(\theta_{L}=\theta_{H}\right)$ and year-round carrying capacity $\left(\phi_{L}=\right.$ $\left.\phi_{H}\right)$ the proportion of migrants is zero and the population consists simply of two resident populations. Second, when differences exist between ranges in seasonality and/or yearround carrying capacity for a migration tactic to exploit, animals from the lowland range migrate to the highland range and out-compete highland residents (as $\mu_{L}<\mu_{H}$ ). This results in a partially migratory population on the lowland range, without residents on the highland range (as is the case with the reference parameter values shown in Fig. 3). Third, when the lowland range would not be viable year-round (i.e.. $\phi_{L} \geq 1$ ), the animals on the lowland range become obligatory migrants without residents in either range. Thus, ideal-free migration $(0<\hat{m} \leq 1)$ will exist whenever the ranges differ in winter mortality (i.e., $\mu_{H}>$ $\left.\mu_{L}\right)$. The proportion of migrants increases in the population

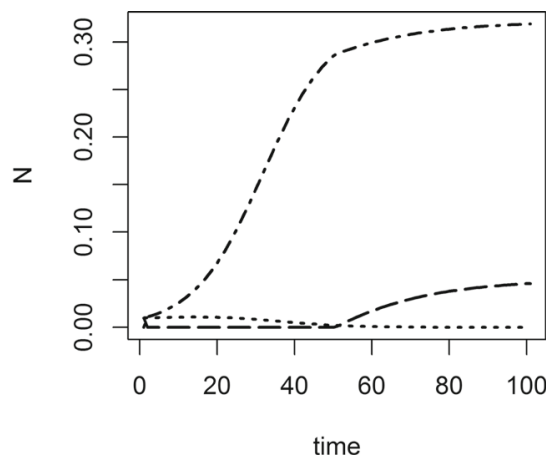

$\phi_{L}=\phi_{H}=0.95$ ). Both populations show partial migration. However, as the year-round carrying capacity of each range decreases towards 0 , the migration behavior of the population moves from partial towards obligatory 


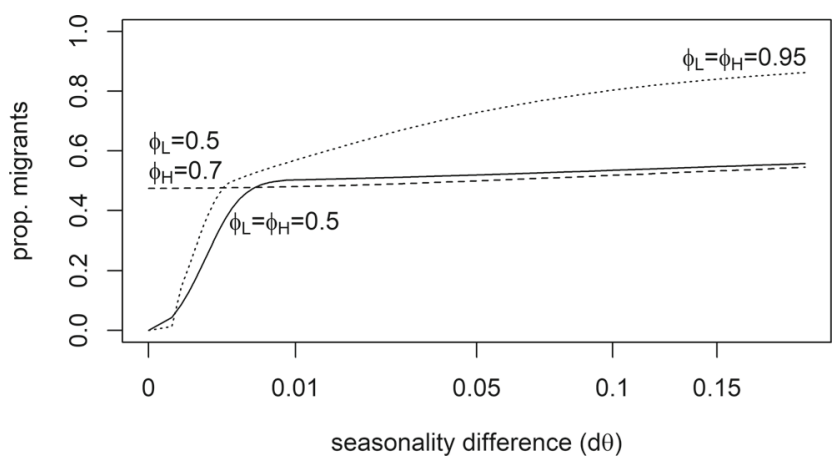

Fig. 4 Proportion of migrants at equilibrium as a function of the seasonality difference between both ranges $\left(d \theta=\theta_{L}-\theta_{H}\right)$ and yearround carrying capacity of each range $\left(1-\phi_{L}\right.$ and $\left.1-\phi_{H}\right)$. The seasonality of the lowland range was fixed $\left(\theta_{L}=0.5\right)$. For migration to take place, the two ranges need to differ in seasonality and/or carrying capacity, in the absence of both the proportion of migrants will be zero. The proportion of migrants increases as the difference in seasonality between both ranges increases, and as the year-round viability of the lowland range decreases

as the year-round carrying capacity on the lowland range decreases (i.e., decrease in $1-\phi_{L}$ ), or as the recruitment on the highland range increases (i.e., increase in $r_{H}$ ). When $\mu_{H}=\mu_{L}$, the proportion of migrants was dependent upon the initial population sizes, because the fitness of migrants and highland range residents is equal when migration is cost-free.

\section{Harvest of a migratory population}

The yields from harvesting a partial migratory population are dependent upon the timing of harvest (Fig. 5), and unsurprisingly on the year-round carrying capacity (i.e., $1-\phi$; Supplementary Fig. 8). Harvest during the summer season, when migrants are on the highland range, gives a higher maximum sustainable yield (MSY), than harvest during the winter season, when migrants are on the lowland range. The winter harvest rate with MSY makes lowland residency not viable (i.e., $\frac{\mu_{L}+h_{L}^{W}}{r_{L}} \geq 1$, with the reference values from Table 2), thereby restricting summer recruitment to the highland range, which results in a lower MSY for winter than summer harvest.

Changes in the yield from summer harvest are most affected by the highland range harvest probability $\left(H_{H}^{S}\right.$; Fig. 5). Beyond intermediate harvest pressures during summer on the lowland range, residency on that range is no longer viable and the population is dominated by migrants; therefore, the yield comes from the harvest of migratory individuals, which during summer are on the highland range. For the same reason, the yield from winter harvest is most affected by the lowland range harvest probability $\left(H_{L}^{W}\right)$, when migrants are back on their range. Interestingly, when the winter harvest pressure increases on the lowland range, a population of highland range residents can grow due to reduced densities of competing immigrants from the lowlands.

Not surprisingly, both yield and harvest probability at the maximum sustainable harvest are lower when yearround carrying capacity (i.e., $1-\phi$ ) on both ranges is lower (Supplementary Fig. 8). At low year-round carrying capacity, the population is a virtually obligatory migrant (Fig. 3), which is reflected in the fact that the yield is largely dependent upon harvest from the range where the migrants are present, i.e., yield from the highlands for summer harvest and yield from the lowlands for winter harvest.

\section{Effects of migration barriers on population size and harvest}

Both migration cost $(c)$ and behavioral avoidance $(b)$ of a barrier lead to a reduction in total population size (Fig. 6). The migration cost and behavioral avoidance of a barrier interact negatively (Supplementary Figs. 9 and 10): with an increasing migration cost $(c)$ the behavioral avoidance effect (b) of the barrier decreases, due to the ceiling on the total barrier effect (when the barrier is maximal, migration no longer occurs). Although a behavioral avoidance generally leads to a decrease in the total population size, a small avoidance effect actually increases the total population size (i.e., $b=1-\frac{m^{*}}{\hat{m}} \approx 0.2$; Fig. $6 \mathrm{~d}$ ) as it decreases the idealfree migration probability towards the migration probability that maximizes average fitness (Fig. 2).

The overall reduction in population size due to barriers is partially buffered by an increase in resident population size, when the year-round carrying capacity is relatively high (i.e., $\phi=0.5$ ), especially in the highland range. This increase in the highland resident population follows the reduced competition from migrant individuals. When the year-round carrying capacity in each range is low (i.e., $\phi=$ 0.95 ), then little buffering will occur and the negative barrier effects on total population size are stronger (Supplementary Figs. 9 and 10).

Also, the maximum sustainable yield (MSY) is negatively affected by both migration cost and behavioral avoidance of barriers (Fig. 6). This decrease is particularly dramatic when the year-round carrying capacity is low (Supplementary Figs. 11 and 12), and little buffering from resident populations takes place.

Paradoxically, barriers can lead to a local increase in yield, despite the overall decrease in the MSY due to barriers. When the year-round carrying capacity is sufficiently high, barriers lead to a local increase in yield from the highland range. Therefore, this barrier-mediated increase in harvest yield from the highland residents results 
Fig. 5 Yield as a function of harvest fraction on the highland range $\left(H_{H}\right)$ and lowland range $\left(H_{L}\right)$ for summer (panel on the left, $H^{S}$ ) and winter harvest (panel on the right, $H^{W}$ ). See Table 2 for all parameter values
Summer Harvest

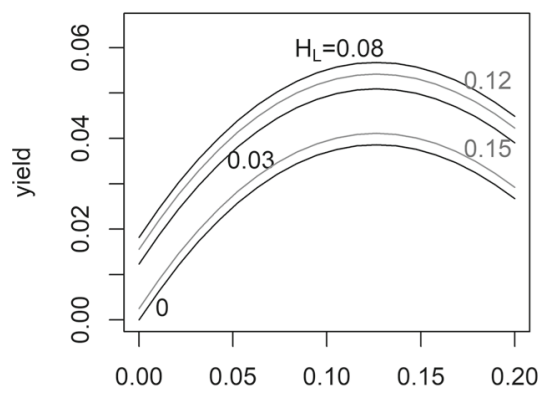

$\mathrm{H}_{\mathrm{H}}$
Winter Harvest

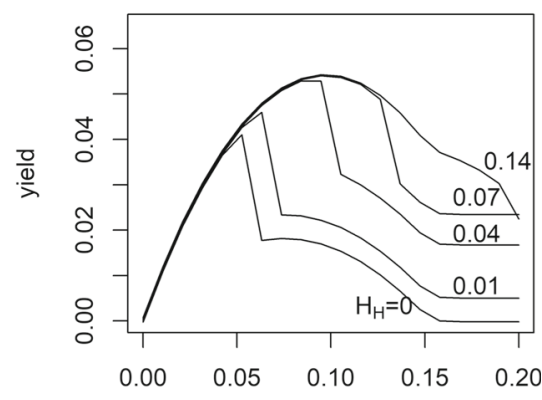

$\mathrm{H}_{1}$ in a more equitable distribution of the yield across both ranges (Fig. 6c and f).

\section{Discussion}

We presented a simple model for the dynamics of a density-dependent migratory population to investigate the effects of changes in seasonality and migration barriers on population size and harvest. Our model predicts partial migration in environments where ranges differ in seasonality and/or year-round carrying capacity. Migration barriers-irrespective of whether they increase the cost of migration or are simply avoided-lead to a reduction in population size and harvest yield. However, when yearround carrying capacity is sufficiently high, this reduction is buffered by an increase in the resident populations. This increase in the resident population can result also in a local increase in harvest yield at the expense of a global decrease in yield due to migration barriers.
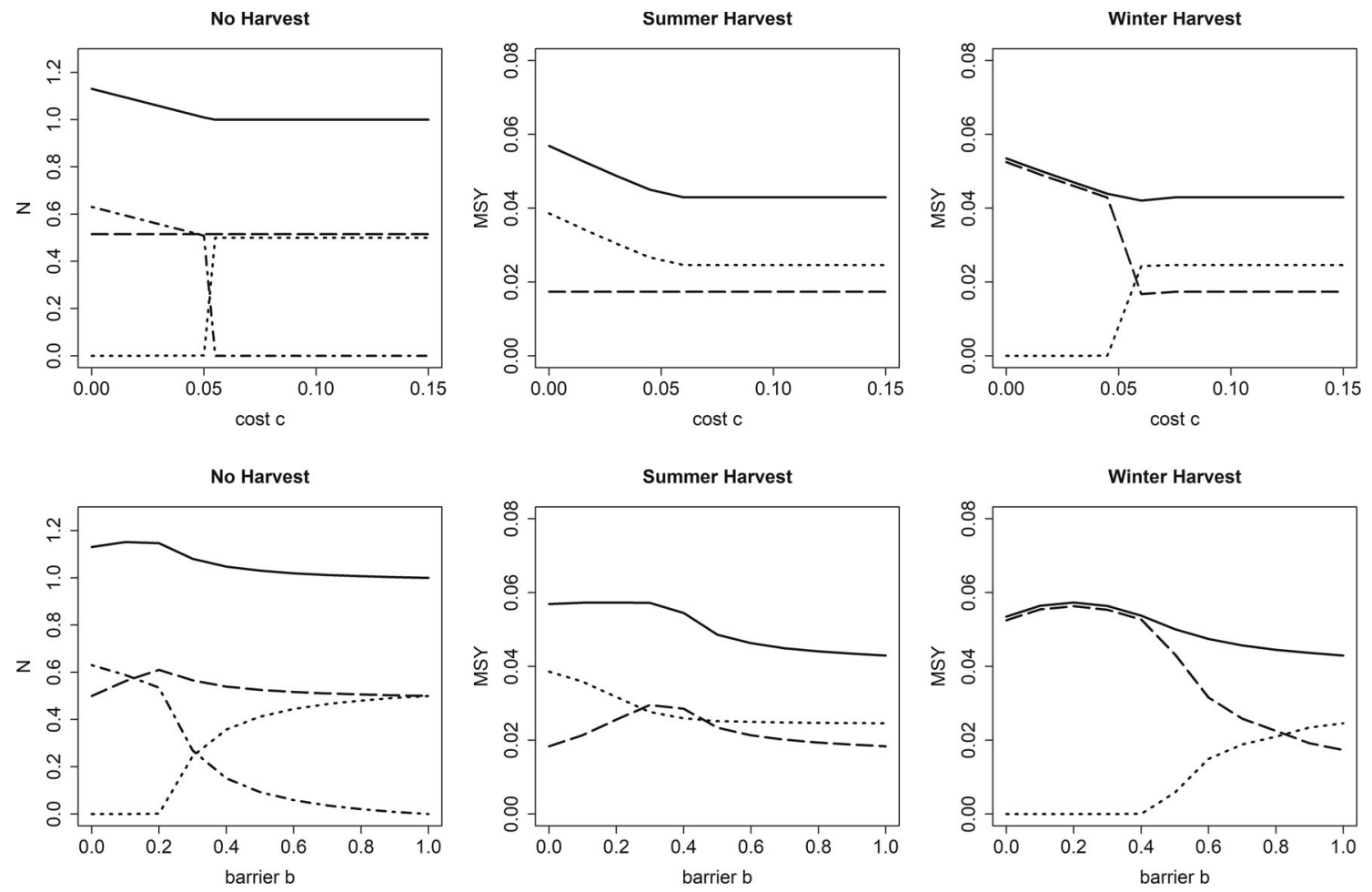

Fig. 6 Population size (panels on the left ) and harvest yield (panels in the center and on the right) as a function of migration cost ( $c$, top row) and non-adaptive barrier avoidance ( $b$, bottom row). Population size in the absence of harvest is shown for residents in the lowland range (dashed line), residents in the highland range (dotted line), migrants (dot-dashed line), and in total (solid line). The yield is shown on the lowland range (dashed line), highland range (dotted line), and in total (solid line) from harvest with the maximum sustainable yield for summer (center panels) and winter harvest (right hand panels). See Table 2 for parameter values 
Our model simplifies the demography of ungulates by omitting sex-, age-, state-dependent migration, etc. Although these different elements will probably affect the finer details of our model's behavior, our main results stem from the migrants experiencing (a) higher reproduction during summer compared to lowland residents and (b) reduced winter mortality compared to highland residents. The higher summer reproduction resulted from a release of density-dependent competition with lowland residents, whereas the lower winter mortality was independent of density. This seasonal structure was inspired by our choice of ungulates in the northern hemisphere as our model species group (Sæther 1997; Gaillard et al. 2000), being the economically most important terrestrial migratory resource subject to harvest. However, we do expect the general dynamics of our model to be applicable to a broader range of migrating species in environments with a different seasonal structure as long as migrants can have an advantage over the residents on both seasonal ranges. By assuming density dependence only in one season, Eq. 9 becomes linear in $m$ and thus mathematically convenient to derive. However, species may experience density dependence on both ranges. Introducing density-dependent mortality on the lowland range into our model could reduce the benefit that migrants have over highland range residents from returning to the lowland range; thus, under certain parameter values, highland range residents can be expected (see Holt and Fryxell 2011). However, a full exploration of the added complexity of this double density dependence on ideal-free migration was beyond the scope of the present paper.

\section{Global warming and changing seasonality}

In an empirical setting, we would only observe winter mortality in the shared range of residents and migrants, while our theoretical setting allows us to explore the effects of the non-observed (expected) mortality of remaining on the highland (recruitment) range. Similar to Mariani et al. (2016), we find density-dependent migration (either partial or obligatory) when seasonal differences exist between both ranges (i.e., $r_{H}>r_{L}$ and/or $\mu_{H}>\mu_{L}$ ). These results confirm the findings by Holt and Fryxell (2011) and Fryxell and Holt (2013) when considering the evolution of a migratory morph. Thus, in seasonal environments, we would expect migration behavior independently of whether it is an ideal-free behavioral choice or genetically fixed.

A primary driver of seasonal migration of ungulates at northern latitudes is snow deposition leading to range contraction in autumn (Nelson 1995; LeResche 1974; Brazda 1953), since snow depth is a major driver of overwinter mortality (Cederlund and Lindström 1983). The response of snow deposition patterns to global warming is affected by the interaction between precipitation and the temperature threshold around freezing (Brown and Mote 2009); therefore, even moderate climate change scenarios can markedly affect future habitat suitability of ungulates at northern distribution ranges (Rivrud et al. 2019). However, whether climate changes will reduce or increase snow cover depends on whether temperature or precipitation is limiting snow accumulation (resp. coastal vs. continental regions, Brown and Mote 2009). Thus, the effects of climate change on migratory populations and their harvest can be opposite in different regions.

Moreover, an increase in weather extremes and variation is expected due to climate change (Coumou and Rahmstorf 2012), which can lead to years when migration becomes a particularly important tactic for a population to deal with such variation spatially (e.g., Stien et al. 2010). In general, the increased variability in living conditions due to climate change will require an increased plasticity in migratory behavior (Moore 2011).

\section{Migration mortality and behavioral avoidance of barriers}

Our approach and results enhance the understanding of how the reported negative effects of migration barriers on population dynamics may arise (reviewed in Bolger et al. 2008). In our analysis, we considered effects from both migration cost and behavioral avoidance of barriers on animal migration (Shepard et al. 2008). The effects of an increased cost to migration or behavioral avoidance of a barrier were similar as both led to a reduction in the migration probability. A migratory population becomes fully resident through either complete behavioral avoidance of the barrier (i.e., $b=1$ ), or when the cost associated to migration outweighs the benefits (i.e., $c>r_{H}\left[1-N_{H}\right]-$ $\left.r_{L}\left[1-N_{L}\right]-\left(h_{H}^{S}-h_{L}^{S}\right)\right)$. In our model, we assumed that animals responded to the increased cost of migration. It is, however, possible that certain species are not responding adequately to the increased mortality associated with a barrier. In such cases, a barrier could have even larger effects on the dynamics of a population.

The increase in population size we found for small behavioral barriers is a consequence of the difference between ideal-free and average-fitness-maximizing migration (Fig. 2); this difference results from the density regulation. With the Ricker-type density regulation in our model, no positive effect would occur from a barrier on the idealfree migration probability when $r_{H} \leq r_{L}$, the ideal-free migration probability would then equal or be lower than the average-fitness-maximizing one.

In the most strongly seasonal environments (i.e., where each seasonal range cannot sustain a population year-round: $1-\phi \leq 0$ ), we expect that the introduction of a strong 
migration costs and/or behavioral avoidance of barrier will lead to a population collapse. However, even when one or both of the seasonal ranges can sustain a resident population a migration barrier often results in a decreased population growth (e.g., Skogland and Mølmen 1980).

\section{Migration, harvest, and management}

Migratory animals create a spatial dependency between areas, which results in spatial subsidies (Semmens et al. 2011) when the societal costs and benefits from a species are season dependent (Skonhoft and Olaussen 2005; Nilsen et al. 2009). Such spatial subsidies are often a challenge for managers, when administrative boundaries are crossed (Boyce 1991). In environments with high year-round carrying capacity, barriers can locally increase populations and harvest yields resulting in a more equitable distribution of costs and benefits thereby reducing societal conflicts. However, such positive barrier effects are likely countered by the decrease in overall population size and harvest yield, when the year-round carrying capacity of the ranges is low (i.e., none or only small resident populations are supported).

In addition, changing harvest and mortality can shift a population from being resident to migratory and vice versa. Empirical studies have documented increased residency following increased mortality during migration due to nonhuman predators (Middleton et al. 2013; Hebblewhite and Merrill 2011). Although several studies have demonstrated the effects of human hunting on the timing of migration (Bechet et al. 2003; Rivrud et al. 2016), we are not aware of studies showing that human harvest has altered the migratory behavior of a population altogether.

The timing of harvest is crucial for the spatial distribution of the yield from a migratory population. Summer harvest will lead to a high yield in the highland range and results in the maximum sustainable yield for partially migratory populations. On the other hand, winter harvest provides the benefits from harvest to the lowland range. For example, the harvest season has been extended to allow for winter harvest of migratory moose to redistribute benefits among landowners in some municipalities of Norway (Skonhoft and Olaussen 2005). Also in red deer, a change in the harvesting season resulted in a marked shift in the spatial distribution of the harvest (Loe et al. 2016). Thus, the timing of the harvest has important consequences for the spatial subsidies that areas provide to each other (Semmens et al. 2011).

Acknowledgments We thank Douglas Morris for helpful feedback on the manuscript.

Funding information Open Access funding provided by Norwegian institute for nature research. This study was funded by the Norwegian Research Council (grant numbers: 251112, 230335, and 255635/E50).
Open Access This article is licensed under a Creative Commons Attribution 4.0 International License, which permits use, sharing, adaptation, distribution and reproduction in any medium or format, as long as you give appropriate credit to the original author(s) and the source, provide a link to the Creative Commons licence, and indicate if changes were made. The images or other third party material in this article are included in the article's Creative Commons licence, unless indicated otherwise in a credit line to the material. If material is not included in the article's Creative Commons licence and your intended use is not permitted by statutory regulation or exceeds the permitted use, you will need to obtain permission directly from the copyright holder. To view a copy of this licence, visit http:// creativecommonshorg/licenses/by/4.0/.

\section{References}

Aikens EO, Kauffman MJ, Merkle JA, Dwinnell SP, Fralick GL, Monteith KL (2017) The greenscape shapes surfing of resource waves in a large migratory herbivore. Ecol Lett 20(6):741750

Avgar T, Street G, Fryxell J (2013) On the adaptive benefits of mammal migration. Can J Zool 92(6):481-490

Bauer S, Hoye BJ (2014) Migratory animals couple biodiversity and ecosystem functioning worldwide. Science 344(6179):552

Bechet A, Giroux JF, Gauthier G, Nichols JD, Hines JE (2003) Spring hunting changes the regional movements of migrating greater snow geese. J Appl Ecol 40(3):553-564

Berger J (2004) The last mile: how to sustain long-distance migration in mammals. Conserv Biol 18(2):320-331

Beyer HL, Gurarie E, Börger L, Panzacchi M, Basille M, Herfindal I, Van Moorter B, R Lele S, Matthiopoulos J (2016) 'you shall not pass!': quantifying barrier permeability and proximity avoidance by animals. J Animal Ecol 85(1):43-53

Bischof R, Loe LE, Meisingset EL, Zimmermann B, Van Moorter B, Mysterud A (2012) A migratory northern ungulate in the pursuit of spring: jumping or surfing the green wave? Amer Natur 180(4):407-424

Bolger DT, Newmark WD, Morrison TA, Doak DF (2008) The need for integrative approaches to understand and conserve migratory ungulates. Ecol Lett 11(1):63-77

Boyce MS (1991) Migratory behavior and management of elk (cervus elaphus). Appl Anim Behav Sci 29(1-4):239-250

Brazda AR (1953) Elk migration patterns, and some of the factors affecting movements in the Gallatin River drainage, Montana. J Wildlife Manag 17(1):9-23

Brooks EN, Lebreton JD (2001) Optimizing removals to control a metapopulation: application to the yellow legged herring gull (larus cachinnans). Ecol Model 136(2):269-284

Brown RD, Mote PW (2009) The response of northern hemisphere snow cover to a changing climate. J Clim 22(8):2124-2145

Byrd RH, Lu P, Nocedal J, Zhu C (1995) A limited memory algorithm for bound constrained optimization. SIAM J Sci Comput 16(5):1190-1208

Cederlund G, Lindström E (1983) Effects of severe winters and fox predation on roe deer mortality. Acta Theriol 28(7):129-145

Chapman BB, Brönmark C, Nilsson JÅ, Hansson LA (2011) The ef partial migration. Oikos 120(12):1764-1775

Costello C, Polasky S (2008) Optimal harvesting of stochastic spatial resources. J Environ Econ Manag 56(1):1-18

Coumou D, Rahmstorf S (2012) A decade of weather extremes. Nat Clim Chang 2(7):491-496

Forrest RE, Walters CJ (2009) Estimating thresholds to optimal harvest rate for long-lived, low-fecundity sharks accounting for selectivity 
and density dependence in recruitment. Can J Fish Aquat Sci 66(12):2062-2080

Fretwell SD, Lucas HL (1969) On territorial behavior and other factors influencing habitat distribution in birds. Acta Biotheor 19(1):16-36

Fretwell SD (1972) Populations in a seasonal environment. Princeton University Press

Fryxell J, Sinclair A (1988) Causes and consequences of migration by large herbivores. Trends Ecol Evol 3(9):237-241

Fryxell J, Holt R (2013) Environmental change and the evolution of migration. Ecol 94(6):1274-1279

Gaillard JM, Festa-Bianchet M, Yoccoz N, Loison A, Toigo C (2000) Temporal variation in fitness components and population dynamics of large herbivores. Ann Rev Ecol Syst 31(1):367-393

Harris G, Thirgood S, Hopcraft JGC, Cromsigt JP, Berger J (2009) Global decline in aggregated migrations of large terrestrial mammals. Endanger Species Res 7(1):55-76

Hebblewhite M, Merrill EH (2011) Demographic balancing of migrant and resident elk in a partially migratory population through forage-predation tradeoffs. Oikos 120(12):1860-1870

Holt RD, Fryxell JM (2011) Theoretical reflections on the evolution of migration. In: Milner-gulland E, fryxell JM, Sinclair ARE (eds). Animal Migration: A Synthesis, Oxford University Press, Oxford, chap 3, pp 17-31

Jaeger JA, Fahrig L (2004) Effects of road fencing on population persistence. Conserv Biol 18(6):1651-1657

Kremen C, Williams NM, Aizen MA, Gemmill-Herren B, LeBuhn G, Minckley R, Packer L, Potts SG, Steffan-Dewenter I, Vázquez DP et al (2007) Pollination and other ecosystem services produced by mobile organisms: a conceptual framework for the effects of land-use change. Ecol Lett 10(4):299-314

Křivan V, Cressman R, Schneider C (2008) The ideal free distribution: a review and synthesis of the game-theoretic perspective. Theo Popul Biol 73(3):403-425

Křivan V, Jana D (2015) Effects of animal dispersal on harvesting with protected areas. J Theor Biol 364:131-138

Lande R, Engen S (1994) Optimal harvesting, economic discounting. Nature 372:3

Lande R, Engen S, Saether BE (2003) Stochastic population dynamics in ecology and conservation. Oxford University Press on Demand

LeResche R (1974) Moose migrations in North America. Nat Can 101:393-415

Ling S, Milner-Gulland E (2008) When does spatial structure matter in models of wildlife harvesting? J Appl Ecol 45(1):63-71

Loe LE, Rivrud IM, Meisingset EL, Bøe S, Hamnes M, Veiberg V, Mysterud A (2016) Timing of the hunting season as a tool to redistribute harvest of migratory deer across the landscape. Eur J Wildlife Res 62(3):315-323

Mariani P, Křivan V, MacKenzie BR, Mullon C (2016) The migration game in habitat network: the case of tuna. Theor Ecol 9(2):219-232

Middleton AD, Kauffman MJ, McWhirter DE, Cook JG, Cook RC, Nelson AA, Jimenez MD, Klaver RW (2013) Animal migration amid shifting patterns of phenology and predation: lessons from a Yellowstone elk herd. Ecol 94(6):1245-1256

Moore TT (2011) Climate change and animal migration. Environ Law 41:393

Mysterud A, Loe LE, Zimmermann B, Bischof R, Veiberg V, Meisingset E (2011) Partial migration in expanding red deer populations at northern latitudes-a role for density dependence? Oikos 120(12):1817-1825

Nelson ME (1995) Winter range arrival and departure of white-tailed deer in northeastern Minnesota. Can J Zool 73(6):1069-1076

Neubert MG (2003) Marine reserves and optimal harvesting. Ecol Lett 6(9):843-849

Nilsen EB, Skonhoft A, Mysterud A, Milner JM, Solberg EJ, Andreassen HP, Stenseth NC (2009) The role of ecological and economic factors in the management of a spatially structured moose Alces alces population. Wildl Biol 15(1):10-23

Osborne MJ (2009) Introduction to Game Theory: International Edition. Oxford University Press, Oxford

R Core Team (2016) R: A Language and Environment for Statistical Computing. R Foundation for Statistical Computing, Vienna. https://www.R-project.org/

Ricker WE (1954) Stock and recruitment. J Fish Board Can 11(5):559_ 623

Rivrud IM, Bischof R, Meisingset EL, Zimmermann B, Loe LE, Mysterud A (2016) Leave before it's too late: anthropogenic and environmental triggers of autumn migration in a hunted ungulate population. Ecol 97(4):1058-1068

Rivrud IM, Meisingset EL, Loe LE, Mysterud A (2019) Future suitability of habitat in a migratory ungulate under climate change. Proc R Soc B 286(1899):20190,442

Sæther BE (1997) Environmental stochasticity and population dynamics of large herbivores: a search for mechanisms. Trends Ecol Evol 12(4):143-149

Sæther BE, Engen S, Solberg EJ (2001) Optimal harvest of agestructured populations of moose alces alces in a fluctuating environment. Wildl Biol 7(3):171-179

Salinas RA, Lenhart S, Gross LJ (2005) Control of a metapopulation harvesting model for black bears. Nat Resour Model 18(3):307321

Sanchirico JN, Wilen JE et al (2001) Dynamics of spatial exploitation: a metapopulation approach. Nat Resour Model 14(3):391418

Semmens DJ, Diffendorfer JE, López-Hoffman L, Shapiro CD (2011) Accounting for the ecosystem services of migratory species: quantifying migration support and spatial subsidies. Ecol Econ 70(12):2236-2242

Shepard D, Kuhns A, Dreslik M, Phillips C (2008) Roads as barriers to animal movement in fragmented landscapes. Anim Conserv 11(4):288-296

Skogland T, Mølmen Ø (1980) Prehistoric and present habitat distribution of wild mountain reindeer at dovrefjell. In: Second international reindeer/caribou symposium. Direktoratet for Vilt-og Ferskvannsfisk, Røros, pp 130-141

Skonhoft A, Olaussen JO (2005) Managing a migratory species that is both a value and a pest. Land Econ 81(1):34-50

Stien A, Loe LE, Mysterud A, Severinsen T, Kohler J, Langvatn R (2010) Icing events trigger range displacement in a high-arctic ungulate. Ecol 91(3):915-920

Trombulak SC, Frissell CA (2000) Review of ecological effects of roads on terrestrial and aquatic communities. Conserv Biol 14(1):18-30

Wilcove DS, Wikelski M (2008) Going, going, gone: is animal migration disappearing. PLoS Biol 6(7):e188 